\title{
Análise de aprendizagem expansiva em interuenção formativa: a inclusão de alunos com deficiência nas séries finais do ensino fundamental em foco
}

\section{Análisis de aprendizaje expansivo en interuención formativa: la inclusión de alumnos con discapacidad en los últimos años de la enseñanza primaria en cuestión The Analysis of Expansive Learning in a Formative Interuention: The Inclusion of Students with Disabilities in the final Years of a Primary School}

\author{
Adriane Cenci* \\ Universidade Federal do Rio Grande do Norte \\ Daniela Vilas Bôas \\ Instituto Proficere \\ Magda Floriana Damiani \\ Universidade Federal de Pelotas
}

Doi: https://doi.org/10.12804/revistas.urosario.edu.co/apl/a.7323

\begin{abstract}
Resumo
O artigo examina uma intervenção formativa, realizada em uma escola, com um grupo de professores que estreava na inclusão de alunos com deficiência em suas turmas e estava apresentando dificuldades. A intervenção buscou ampliar a compreensão sobre inclusão e, consequentemente, a mudança das práticas em relação aos alunos incluídos. Foram realizadas 10 sessões, de março a dezembro de 2014, planejadas a partir da proposta de aprendizagem expansiva, definida por Engeström. A análise foi organizada com base nas ações do ciclo de aprendizagem expansiva: questionamento, análise, modelagem da nova solução, exame do novo modelo, implementação do novo
\end{abstract}

modelo, reflexão sobre o processo e consolidação da nova prática. Foram desenvolvidas, durante a intervenção, três ações capazes de produzir a aprendizagem expansiva: protocolo de organização da inclusão na escola, agenda para os alunos incluídos e estabelecimento de trabalho coordenado entre professores da sala regular e da sala de recursos. Ao final da intervenção, constatou-se que nenhuma das três consolidou-se. Concluiu-se que, para haver transformação, seria necessário desenvolvimento de agency, de engajamento dos sujeitos no processo de mudança, o que não aconteceu.

Palavras-chave: inclusão escolar, aprendizagem expansiva, formação de professores, intervenção formativa.

Dirigir correspondencia a Adriane Cenci, Universidade Federal do Rio Grande do Norte, Brasil. Correio eletrônico: adricenci@ gmail.com

Para citar este artigo: Cenci, A., Bôas, D. V., \& Damiani, M. F. (2020). Análise de aprendizagem expansiva em intervenção formativa: a inclusão de alunos com deficiência nas séries finais do ensino fundamental em foco. Avances en Psicología Latinoamericana, 38(1), 118-134. https://doi.org/10.12804/revistas.urosario.edu.co/apl/a.7323 


\section{Resumen}

El artículo examina una intervención formativa en una escuela, en la cual un grupo de profesores tenía dificultades con la inclusión de alumnos con discapacidad en las aulas. La intervención buscó expandir la comprensión sobre inclusión y el cambio de las prácticas en relación con los alumnos incluidos. Partiendo de la propuesta de aprendizaje expansivo, definida por Engeström, se planearon 10 sesiones, de marzo a diciembre de 2014. Se organizaron análisis a partir de acciones del ciclo de aprendizaje expansivo: cuestionamiento, análisis, modelado de la nueva solución, examen del nuevo modelo, implementación del nuevo modelo, reflexión sobre el proceso y consolidación de la nueva práctica. Se desarrollaron tres intentos de aprendizaje expansivo: el protocolo de organización de la inclusión en la escuela, la agenda para los alumnos incluidos y el establecimiento de un trabajo coordinado entre profesores de clases regulares y de clases especiales. Al final de la intervención, se constató que ninguna de estas se consolidó. Por consiguiente, se concluyó que mientras no hubiera el desarrollo de agency por parte de los sujetos involucrados, no habría transformación. Palabras clave: inclusión escolar, aprendizaje expansivo, formación de profesores, intervención formativa.

\section{flbstract}

This study analyzed a formative intervention with a group of teachers that were dealing with the inclusion of students with disabilities for the first time and facing difficulties. The intervention's aim was to expand the understanding of inclusion and, consequently, change the pedagogical practices related to the included students. It was comprised of ten sessions (March to December 2014) planned according to Engeström's expansive learning proposition. The analysis was organized according to the cycle of expansive learning: questioning, analysis, modeling and testing of the new solution, the implementation of the new model, reflection of the process, and consolidation of the new practice. There were three attempts of expansive learning during the intervention: a protocol to organize the process of inclusion, the development of a school diary to be used by the included students, and an attempt to coordinate the work of the teachers from the regular classes and the resource room. At the end of the intervention, none of the three attempts was consolidated. Finally, the development of the agency would be paramount to allow transformation, which did not happen.

Keywords: School inclusion, expansive learning, teachers' training, formative intervention.

Os problemas enfrentados por indivíduos e por organizações, imersos em uma sociedade em constante transformação, exigem análises e soluções que, com frequência, precisam ser elaboradas pelos próprios sujeitos que vivenciam tais problemas. Nessa perspectiva, o conceito de aprendizagem expansiva (Engeström, 2016, 2000, 2001; Engeström \& Sannino, 2010; Engeström, Rantavuori, \& Kerosuo, 2013) tem sido empregado, com frequência, na tentativa de encontrar a solução dos problemas vivenciados em diferentes instituições, desde empresas até órgãos públicos de diferentes áreas, como educação, segurança e saúde.

A pesquisa aqui apresentada foi desenvolvida junto a professores do $6^{\circ}$ ano de uma escola pública do interior do estado do Rio Grande do Sul, Brasil, que se depararam com uma situação nova: a inclusão de dois alunos com deficiência intelectual em suas salas de aula. No entanto, a organização pedagógica desse grupo não contemplava tais alunos e o sucesso da inclusão requeria que eles modificassem tal organização. Para tanto, foi planejada e implementada uma intervenção formativa, com vistas a desenvolver um novo padrão de atividade: uma organização pedagógica inclusiva, com o envolvimento de todos os professores. A maior parte deles recebia alunos com deficiência pela primeira vez e, à época da intervenção, já trabalhava com eles há cerca de um mês, apresentando dificuldades. Define-se como objetivo do texto analisar os dados dessa intervenção formativa, a partir da proposta de Engeström (1999, 2001, 2007, 2010, 2011, 2016; Engeström \& Sannino, 2010), 
descrevendo as ações de aprendizagem expansiva para compreender o processo.

Destaca-se que não há, no Brasil, política consistente de formação continuada de professores que os subsidie no trabalho com alunos com deficiência nas classes regulares - ainda que, desde o ano de 2008, com a implementação da Política Nacional de Educação Especial na Perspectiva da Educação Inclusiva (Brasil, 2008), a matrícula desse grupo de alunos, na escola regular, seja mandatória. Tal política enfatiza a formação de profissionais para o atendimento educacional especializado, em sala de recursos multifuncional, aos alunos com deficiências, com transtorno global do desenvolvimento (termo, posteriormente, substituído por transtorno do espectro autista) e com altas habilidades/ superdotação (Brasil, 2008), apostando que esses profissionais possam ser, eles também, multifuncionais, aposta que as formações não contemplam (Borowski, 2010; Garcia, 2013). O atendimento especializado é complementar ou suplementar ao ensino de classe regular, deve ser (mas nem sempre é) ofertado no contraturno desse ensino, tem frequência variável - geralmente uma ou duas vezes por semanas, com duração de cerca de uma hora. Glat (2018) destaca que é imprescindível haver parceria efetiva entre os profissionais do atendimento especializado e os de classe comum, superando visão estereotipada de que o aluno com deficiência é de responsabilidade do professor especialista em Educação Especial. Tal cultura de colaboração, entretanto, precisa ser construída ainda.

A formação continuada de professores de classe regular para a inclusão tem sido preocupação de pesquisadores brasileiros da área de Educação Especial (Tavares, Santos \& Freitas, 2016). Dentre as abordagens adotadas nas formações, encontram-se pesquisas as pesquisas colaborativas (Souza $\&$ Mendes, 2017). Os trabalhos desenvolvidos em algumas pesquisas (Fidalgo, 2018; Magalhães \& Soares, 2016; Toledo \& Vitaliano, 2012 ; Vitaliano, 2019) aproximam-se daquele aqui relatado, principalmente, por visar à implementação de práticas inclusivas, a partir de intervenções que contam com a parceria entre pesquisador e profissionais da escola que atuam junto aos alunos com deficiência (Souza \& Mendes, 2017).

A intervenção aqui analisada também pode ser entendida na perspectiva de formação continuada que teve como propósito oferecer subsídios à discussão da inclusão no contexto da escola regular. No entanto, a perspectiva de análise, que buscou analisar os movimentos (as ações) de aprendizagem expansiva que ali ocorreram não foi encontrada em outras investigações acerca da inclusão escolar; sendo ainda uma novidade no campo da educação inclusiva no Brasil.

\section{Referencial teórico}

O conceito de aprendizagem expansiva difere daquele da aprendizagem tradicional, pois considera o processo a partir do desenvolvimento coletivo e não a partir do desenvolvimento individual (Engeström, 2001). A aprendizagem expansiva é coletiva, ocorre em um sistema de atividade - este entendido como uma formação relativamente estável de um grupo de pessoas que compartilham um mesmo objeto orientador de suas atividades e têm seus próprios instrumentos, suas regras e formas de divisão de trabalho (Engeström, 2016). Na aprendizagem expansiva, não se definem mestres e aprendizes, pois o potencial expansivo está na articulação entre os sujeitos e não no conhecimento isolado de um deles. É a aprendizagem que mobiliza o sistema, cria uma nova instrumentalidade -novos modelos, novas ferramentas, novos modos de trabalho - expandindo seu objeto (Engeström, 2001). Isso não quer dizer que a aprendizagem expansiva é, desde o início, ampla e espalhada pelo sistema de atividade; pelo contrário, com frequência, ela inicia como algo pequeno, mas com potencial para expansão.

Para que a aprendizagem expansiva seja desenvolvida em um sistema de atividade, é necessária a 
mobilização dos sujeitos, tendo em vista sua intencionalidade para mudar sua atividade. Aqui temos a emergência do conceito de agência (agency), que diz respeito ao rompimento, consciente e intencional, por parte dos sujeitos, com um dado padrão de atividade, apoiado por instrumentos mediadores, visando à conquista de protagonismo para assumir mudanças nesse padrão com base no domínio do próprio comportamento e do engajamento em ações de transformação (Sannino, Engeström \& Lemos, 2016; Virkkunen, 2006).

A iniciativa para mudança estaria, desse modo, ligada a artefatos externos dos quais o sujeito se apropria para redefinir a atividade. Nota-se aqui o uso da ideia de dupla estimulação, ${ }^{1}$ proposta por Vygotsky (1993), atualizada pelos autores contemporâneos da Teoria Histórico-Cultural da Atividade (Engeström, 2007, 2011; Engeström, Sannino \& Virkkunen, 2014; Sannino \& Laitinen, 2015; Sannino, Engeström \& Lemos, 2016). Tal ideia é tomada como princípio das intervenções formativas - nas quais pesquisadores fomentam a elaboração/utilização de mediadores para subsidiar o processo de tomada de consciência das contradições de um sistema de atividade que está enfrentando problemas e dar suporte às ações que pretendem transformá-lo.

Para compreender o desenvolvimento da aprendizagem expansiva em um sistema de atividade, deve-se conhecer a estrutura da atividade. Leontiev (1978, 1983), autor da base conceitual da Teoria da Atividade, e Engeström (1999, 2007, 2011, 2017), autor que segue desenvolvendo essa Teoria, destacam que a atividade é orientada por um objeto. É preciso, primeiramente, esclarecer esse

O princípio da dupla estimulação está ancorado na ideia de mediação, de utilizar estímulos externos para interferir em determinada conduta e orientar a resolução de problemas. Vygotsky propõe tal princípio para estudar, por exemplo, a formação de conceitos (Vygotsky, 1993), a memória mediada (Vygotsky \& Luria, 1996), nos quais oferecia estímulo auxiliar (ou segundo estímulo) juntamente com o problema a ser resolvido e observava como os sujeitos se apropriavam deles para resolver tal problema. conceito. O objeto corresponde ao que Leontiev $(1978,1983)$ denomina de motivo da atividade. O objeto, que pode ser tanto real quanto ideal (tanto material quanto imaginado), atende às necessidades do sujeito da atividade. Não existe necessidade em si, ela é sempre necessidade de algo, ou seja, apenas no objeto, a necessidade define-se (objetiva-se), em outras palavras, o motivo toma forma no objeto da atividade.

A estrutura da atividade deve ser compreendida partindo da distinção entre atividade, ação e operação. A atividade, como dito, refere-se ao processo pelo qual o ser humano satisfaz uma necessidade e, com frequência, não é passível de ser apreendida apenas por observação, pois está relacionada aos motivos dos sujeitos da atividade. Ações têm início e fim definidos, são conscientes, têm objetivos claros para o sujeito. Já as operações são processos automatizados, não conscientes, mas podem ser trazidos à consciência pelo sujeito, se as condições de realização de tais operações forem alteradas. Assim, a atividade é compreendida como o sistema amplo que só existe na forma de uma série de ações dirigidas para alcançar objetivos. As ações, por sua vez, dependem dos processos já automatizados, as operações.

Por exemplo, ler este texto, para você, pode ser uma atividade se o objeto for o texto em si, se a compreensão do texto for o motivo. Pode ser uma ação, se você estiver lendo para fazer uma revisão sistemática de textos para escrever outro artigo (nesse caso a escrita da revisão sistemática é o motivo). E as operações são os processos automatizados realizados durante a leitura: desde a decodificação do escrito até as anotações e os destaques.

Esses três níveis — atividade, ação, operaçãoalteram-se de acordo com os motivos dos sujeitos. Seguindo no exemplo anterior, no caso de o motivo que levou você a ler este texto ter sido o de utilizá-lo na escrita de seu artigo, mas se, durante a leitura, você dedicar-se à compreensão de todo seu conteúdo por tê-lo considerado interessante 
e isso passar a ser a razão principal da leitura, o que era ação transformou-se em (novo) motivo. O oposto também pode acontecer —o que era motivo transformar-se em ação- se, por exemplo, um artigo que você está escrevendo for um requisito para aprovação em determinado curso. Nesse caso, escrevê-lo não é o motivo, mas uma ação subordinada à atividade que tem como objeto a aprovação no curso. Por isso, a análise de uma atividade requer que se capture o seu motivo, pois uma mesma tarefa pode ser atividade, ação ou operação. Apenas pela aparência, não é possível apreender a essência da atividade.

Uma vez que a atividade se define a partir dos motivos dos sujeitos e não é possível observá-la diretamente; o desenvolvimento da atividade pode ser acompanhado por meio das ações que a compõem. Assim, para acompanhar a aprendizagem expansiva, além de buscar perceber as mudanças no objeto da atividade, podem-se analisar as ações levadas a cabo pelos sujeitos dessa atividade (Engeström, Rantavuori \& Kerosuo, 2013).

Em um modelo ideal de aprendizagem expansiva, a sequência das ações é a seguinte: 1) questionamento; 2) análise; 3) modelagem da nova solução; 4) exame do novo modelo; 5) implementação do novo modelo; 6) reflexão sobre o processo; e 7) consolidação da nova prática (Engeström, 1999).
O modelo do ciclo de aprendizagem expansiva está ilustrado na figura 1.

A primeira ação do ciclo consiste em questionar, criticar, rejeitar aspectos da atividade atual. A segunda ação é analisar a situação; buscando compreender as causas e os mecanismos que levaram a ela. Duas formas básicas para a realização dessa análise são ressaltadas: a histórico-genética, que busca explicar a situação traçando sua origem e evolução histórica, e a atual-empírica, que busca explicar a situação construindo uma imagem (um esquema) de suas relações sistêmicas internas. Daí, parte-se para a terceira ação, que visa a modelar (desenhar) novas práticas por intermédio de um meio observável, ou seja, construir um modelo explícito e simples, dessas novas práticas, que ofereça uma solução àquela considerada problemática. A quarta ação é examinar o modelo (desenvolvido na ação 3 ), experimentando-o de modo a compreender plenamente sua dinâmica, seu potencial e suas limitações. A quinta ação é a implementação do modelo, sua aplicação. A sexta ação consiste em refletir sobre e avaliar o processo de aprendizagem expansiva levado a cabo. A sétima ação, por fim, é a que visa a consolidar as novas práticas desenvolvidas. É importante pontuar que tal sequência não é fixa. Nas intervenções e, principalmente, nos eventos cotidianos, a aprendizagem expansiva ocorre em

7. Consolidação da nova prática

6. Reflexão sobre o processo

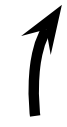

5. Implementação do novo modelo

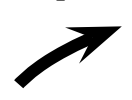

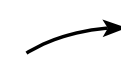

1. Questionamento

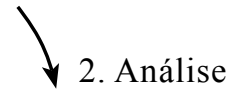

2.1 Análise histórica

2.2 Análise atual e empírica

3. Modelagem da nova solução

4. Exame do novo modelo

Figura 1. Esquema que representa a sequência das ações em um ciclo de aprendizagem expansiva Fonte: Engeström (1999, p. 38). 
um movimento que não é rígido. A sequência, contudo, é útil, para refletir sobre o processo e planejar as mudanças.

\section{Metodologia: A intervenção formativa}

São características das pesquisas do tipo intervenção formativa a intencionalidade de produzir mudanças em um sistema de atividade e o cuidado na implementação de ações que as possam viabilizar (Damiani et al, 2013; Engeström, 2011). A organização da intervenção aqui apresentada buscou inspiração no modelo do Laboratório de Mudança (Engeström, 2007, 2011; Virkkunen \& Newnham, 2013), que oferece uma série de ferramentas para planejar uma intervenção com o intuito de envolver os participantes em ações que irão gerar discussão e implementação de mudanças.

Participaram da intervenção, aqui analisada, os 12 professores do $6^{\circ}$ ano, a professora da sala de recursos, a coordenadora pedagógica e a orientadora educacional da escola que solicitou ajuda, todos envolvidos no processo de inclusão de dois alunos com deficiência intelectual nas séries finais do ensino fundamental. ${ }^{2}$

2 Todos os participantes estavam cientes da pesquisa e concordaram em participar, assinando Termo de Consentimento Livre e Esclarecido. A pesquisa também obteve autorização do Comitê de Ética, com o parecer número 715.236, para o projeto intitulado "A inclusão de alunos com necessidades especiais: discutindo e transformando as práticas na escola".
Foram realizadas 10 sessões, entre março e dezembro de 2014, na escola, durante o horário de trabalho, com duração de cerca de uma hora. As sessões foram planejadas pelas pesquisadoras, buscando responder à demanda apresentada pela escola.

Todas as sessões foram gravadas em vídeo e áudio e transcritas na íntegra. Contou-se com cerca de 8 horas e 21 minutos de gravação, totalizando 219 páginas. Para trabalhar com esse corpus, utilizou-se o software para análise de dados qualitativos QSR NVivo 10.

O quadro 1 apresenta um panorama geral da intervenção, informando o número de participantes, os objetivos e os artefatos mediadores presentes em cada sessão. Tais informações permitem compreender o contexto em que foram produzidos os dados posteriormente analisados.

A análise textual discursiva (Moraes, 2003) orientou o trabalho de organização e categorização dos dados. As categorias foram estabelecidas com base no referencial teórico, o que permitiu traçar o desenvolvimento da aprendizagem expansiva a partir das falas dos participantes da intervenção.

A aprendizagem expansiva foi expressa no desenvolvimento de três propostas: 1) um protocolo de organização da inclusão na escola; 2) uma agenda para os alunos incluídos; e 3) o estabelecimento de trabalho coordenado entre professores da sala regular e sala recursos. As duas primeiras materializaram-se em ferramentas, a terceira tomou forma na reorganização do trabalho. Os dados, no entanto, sugerem que, talvez, seja preferível dizer

Tabela 1.

Síntese das sessões da intervenção: data, número de participantes, objetivos e artefatos mediadores

\begin{tabular}{ccll}
\hline $\begin{array}{c}\text { Sessão/ } \\
\text { Data }\end{array}$ & Part. & \multicolumn{1}{c}{ Objetivos } & Artefatos mediadores \\
\hline 1 & 15 & $\begin{array}{l}\text { Conhecer o contexto no qual ocorreria a inter- } \\
\text { venção. }\end{array}$ & Perguntas e anotações no quadro. \\
$25 / 03$ & 9 & $\begin{array}{l}\text { Discutir os documentos legais que delineiam a } \\
\text { inclusão escolar, esclarecendo dúvidas e con- } \\
\text { fusões conceituais. }\end{array}$ & Documentos legais. \\
\hline $16 / 04$ & & \\
\hline
\end{tabular}




\begin{tabular}{|c|c|c|c|}
\hline $\begin{array}{l}\text { Sessão/ } \\
\text { Data }\end{array}$ & Part. & Objetivos & Artefatos mediadores \\
\hline $\begin{array}{c}3 \\
28 / 04\end{array}$ & 13 & $\begin{array}{l}\text { Tornar claros os procedimentos adotados na es- } \\
\text { cola em relação aos alunos incluídos e as pessoas } \\
\text { responsáveis por tais procedimentos. }\end{array}$ & $\begin{array}{l}\text { Apresentação de síntese da legislação, do nome } \\
\text { e diagnóstico dos alunos do } 6^{\circ} \text { ano atendidos na } \\
\text { sala de recursos. } \\
\text { Apresentação das questões iniciais para a cons- } \\
\text { trução de um Protocolo de Organização (en- } \\
\text { volvendo as regras e a divisão do trabalho em } \\
\text { relação à inclusão). }\end{array}$ \\
\hline $\begin{array}{c}4 \\
19 / 05\end{array}$ & 10 & $\begin{array}{l}\text { Seguir a discussão da organização da escola em } \\
\text { relação aos alunos incluídos e construir um pro- } \\
\text { tocolo para orientar as ações das pessoas. }\end{array}$ & $\begin{array}{l}\text { Modelos, construídos pelos participantes, repre- } \\
\text { sentando a organização da escola e o Protocolo } \\
\text { de Organização. }\end{array}$ \\
\hline $\begin{array}{c}5 \\
09 / 06\end{array}$ & 9 & $\begin{array}{l}\text { Apresentar a sala de recursos aos professores e } \\
\text { estabelecer pontes entre o atendimento especiali- } \\
\text { zado e o da sala regular. }\end{array}$ & $\begin{array}{l}\text { Sala de recursos, juntamente com as explicações } \\
\text { da professora responsável por ela (obs.: a sessão } \\
\text { foi realizada nessa sala). }\end{array}$ \\
\hline $\begin{array}{c}6 \\
07 / 08\end{array}$ & 9 & $\begin{array}{l}\text { Discutir a aprendizagem dos dois alunos com } \\
\text { deficiência incluídos no } 6^{\circ} \text { ano. }\end{array}$ & $\begin{array}{l}\text { Conceitos de Vygotsky, acerca da relação entre } \\
\text { aprendizagem e desenvolvimento, zona de desen- } \\
\text { volvimento proximal e mediação. }\end{array}$ \\
\hline $\begin{array}{c}7 \\
20 / 08\end{array}$ & 9 & $\begin{array}{l}\text { Discutir a aprendizagem dos dois alunos com } \\
\text { deficiência incluídos no } 6^{\circ} \text { ano. }\end{array}$ & $\begin{array}{l}\text { Conceito de zona de desenvolvimento proximal, } \\
\text { apresentado em diferentes modelos para explicar } \\
\text { a relação entre aprendizagem e desenvolvimento, } \\
\text { a partir de exemplos, citados pelos participantes, } \\
\text { relativos à rotina de sala de aula. }\end{array}$ \\
\hline $\begin{array}{c}8 \\
16 / 09\end{array}$ & 9 & $\begin{array}{l}\text { Apresentar as famílias e suas percepções em } \\
\text { relação aos seus filhos com deficiência, seus } \\
\text { processos de aprendizagem e o papel que a } \\
\text { escola vem exercendo na promoção (ou não) de } \\
\text { situações de aprendizagem. }\end{array}$ & $\begin{array}{l}\text { Fala dos pais (transcrição das entrevistas proje- } \\
\text { tada). }\end{array}$ \\
\hline $\begin{array}{c}9 \\
10 / 11\end{array}$ & 10 & $\begin{array}{l}\text { Problematizar o processo de inclusão dos dois } \\
\text { alunos com deficiência, mostrando que eles se } \\
\text { percebiam à margem da aprendizagem. }\end{array}$ & $\begin{array}{l}\text { Fala dos alunos com deficiência (transcrição das } \\
\text { entrevistas projetada). }\end{array}$ \\
\hline $\begin{array}{c}10 \\
08 / 12\end{array}$ & 10 & $\begin{array}{l}\text { Resgatar as discussões das sessões anteriores não } \\
\text { as deixando apagarem-se. Retrospectiva. }\end{array}$ & $\begin{array}{l}\text { As próprias falas dos participantes, em trechos } \\
\text { das transcrições das sessões anteriores e questio- } \\
\text { namentos que retomam as discussões passadas, } \\
\text { projetados nas apresentações. }\end{array}$ \\
\hline
\end{tabular}

que o que ocorreu foram aprendizagens potencialmente expansivas, pois as propostas não chegaram a se consolidar para transformar a atividade. Nesse sentido devem ser consideradas como ações transicionais - transitional actions - (Sannino, 2008), ou seja, ações que não transformaram a atividade, mas a modificaram de alguma forma, pois esta não permaneceu a mesma que era antes da intervenção.

A análise dos dados foi realizada da seguinte forma: primeiramente, foram destacadas no corpus as três propostas que se entendeu apresentarem potencial de aprendizagem expansiva. O passo seguinte foi destacar as ações presentes em cada ciclo de aprendizagem [potencialmente] expansiva - relembrando: questionamento, análise, modelagem da nova solução, exame do novo modelo, implementação do novo modelo, reflexão sobre o processo e consolidação da nova prática. Para a análise que segue, tomam-se como fios condutores essas ações de aprendizagem expansiva. 


\section{O desenvolvimento da aprendizagem expansiva}

A aprendizagem expansiva é abordada desde as ações do ciclo ilustrado na figura 1. Tal sequência de ações, como já apontado anteriormente, não é uma regra. De todo modo, as intervenções formativas tomam tal sequência para orientar as discussões no sentido de avançar desde o questionamento, para a análise, para a modelagem, para o exame, para a implementação, para a reflexão até a consolidação das mudanças. O ciclo de aprendizagem expansiva tanto orienta o planejamento da intervenção, quanto a análise de seus resultados, no sentido de acompanhar quais ações se desenvolveram e entender como a aprendizagem expansiva se consolidou ou não. Tal perspectiva foi adotada na intervenção aqui relatada.

A primeira ação do ciclo, a ação desencadeante da aprendizagem expansiva, o questionamento, aparece como críticas e/ou rejeição à configuração atual da atividade: dirige-se ao objeto (no caso, a inclusão escolar) de modo amplo e vai, depois, delineando-se em ações dirigidas à elaboração de soluções, que emergem por meio de modelos e ideias que vão surgindo entre os participantes. A ação de questionar expressa-se quando há uma necessidade (Engeström, Rantavuori \& Kerosuo, 2013) e, nesta intervenção, o estado de necessidade que gerou os primeiros questionamentos foi a sensação de despreparo dos professores e profissionais, envolvidos na inclusão, que não sabiam o que fazer diante dos alunos com deficiência intelectual inseridos em suas salas de aula. Essa sensação é ilustrada no diálogo abaixo:

P9: ${ }^{3}$ Outra palavra, no meu caso, acho que é insegurança.

Os participantes serão identificados por letras maiúsculas. P refere-se aos professores. Como são vários, aparecerão enumerados: P1, P2, P3... SR refere-se à professora da sala de recursos. $\mathrm{CP}$ refere-se à coordenadora pedagógica. $\mathrm{OE}$ refere-se à orientadora educacional. Os estudantes serão indicados com a letra E; como há mais de um estudante mencionado, procedeu-se, igualmente, a enumeração: E1, E2,...
P4: Eu também acho. É verdade.

P9: Eu me sinto insegura. Sem saber como.

P12: Eu tenho uma palavra: despreparo.

P4: Eu também.

CP: Foi o que eu disse. Exatamente o que eu disse.

(Sessão 1)

A mais alta incidência de ações de questionamento ocorreu na primeira sessão. Porém, tal ação segue presente ao longo de toda intervenção, denotando a dificuldade em avançar para o desenvolvimento e a implementação de propostas que pudessem auxiliar na superação dos sentimentos de despreparo dos professores. O questionamento aparecia com manifestações de desamparo, críticas à política de inclusão escolar e às condições inadequadas do sistema escolar brasileiro para efetivação de uma escola inclusiva:

P5: Então eu te pergunto uma coisa, a E8, que tá agora no $3^{\circ}$ ano, não diz uma palavra, não escreve nada, tem uma cuidadora pra estar ali de plantão com ela, qual é o objetivo dessa criança na escola?

(Sessão 6)

As ações de questionamento, voltadas à inclusão que vivenciavam, encaminharam as três atividades de aprendizagem expansiva propostas: 1) protocolo de organização da inclusão na escola, 2) agenda para os alunos incluídos e 3) coordenação entre professores da sala regular e da sala de recursos.

É preciso esclarecer que as mesmas ações de questionamento iniciam os três ciclos de aprendizagem expansiva. Seguindo na discussão dos dados, nota-se que a sequência das ações se irá diferenciar conforme a proposta que se delineia para dar conta daquela necessidade expressa inicialmente. O delineamento das propostas considerou essa necessidade e foi sendo definido com as escolhas dos artefatos mediadores e dos objetivos de cada sessão da intervenção (conforme apresentado no tabela 1). 
A ação do ciclo de aprendizagem expansiva que vem na sequência do questionamento, é a análise. Ela busca entender os porquês das dificuldades enfrentadas, definindo os problemas e as contradições por trás deles, por meio de análises que utilizam informações do momento presente e da história daquela atividade e do sistema de atividade em que está sendo levada a cabo (Engeström, 2000; Engeström \& Sannino, 2010). A análise relacionada ao protocolo de organização suscitou a discussão sobre as responsabilidades de cada profissional da escola em relação à inclusão, ganhando espaço ao ficar explícita, ainda na primeira sessão, a falta de informações básicas, como a de quem eram os alunos com deficiência do $6^{\circ}$ ano.

P11: Eu sou a P11 [fala seu nome], professora de espanhol, sou manhã e tarde, não só área, currículo também. E concordo com ela, com laudo não tenho nenhum, mas eu acho que tenho alunos especiais.

P4: Mas tu não tem o $6^{\circ}$ ano?

P11: Tenho, mas é o que eu to dizendo.

P4: No $6^{\circ}$, com laudo tem uns quantos.

P5: Tem o E3, tem a E1, o...

CP: Gente, tem dois só. Com laudo, 2.

(Sessão 1)

As ações de análise relacionadas à agenda, segunda proposta gerada pelo grupo, estão relacionadas à discussão do papel da família na escolarização dos filhos com deficiência, ressaltando que estas se envolviam pouco com as questões escolares. Os apontamentos relativos a esse fato fizeram-se presentes ao longo das sessões, desde a primeira; porém, na oitava sessão, quando foram apresentados os excertos das entrevistas com os pais, lançou-se luz sobre o descuido da escola em estabelecer comunicação com as famílias e foi sendo expandido o escopo da discussão, modificando inclusive a visão que os professores tinham acerca dos pais dos alunos com deficiência. No início da oitava sessão, ao ver os primeiros excer- tos das entrevistas com os pais projetados, alguns professores ainda tentaram manter a posição das sessões anteriores, ou seja, a de responsabilizar os pais por serem negligentes em relação às questões escolares dos filhos:

P3: Ali, quando diz "faz os temas com os filhos", eu discordo.

Pesquisadora: Tá, vamos ver o que eles vão falar. Quando eles [os pais] falam dos temas, como os alunos não copiam, quando eles vão olhar os cadernos, não tem tema. Então eles vão fazer o tema, mas eles não sabem se tem tema.

P3: É só perguntar pro professor, quando vem buscar.

SR: Mas quantos professores eles têm? Aí tu tem aula com ele, lá no meio da tarde, aí... mas isso vai aparecer.

(Sessão 8)

As ações de análise que abordam a coordenação entre sala regular e sala de recursos também foram ocorrendo ao longo das sessões, sendo ressaltada a ausência de diálogo entre os professores da classe regular e com a professora que atendia esses alunos na sala de recursos. Tal distanciamento tornava isolado o trabalho de cada um e acarretava o desconhecimento acerca do que estava sendo realizado com os alunos em outros espaços da escola.

Pesquisadora: [...] Outra questão é a relação entre o trabalho desenvolvido na sala regular e na sala de recursos. Como o professor da sala de recursos sabe o que acontece na sala regular e o professor da classe regular sabe o que é feito na sala de recursos? Tem essa relação?

[Vários acenam negativamente com a cabeça - quase unanimemente]

P3: Não. Uma coisa que eu tenho que fazer. E aí eu tenho até vergonha de dizer, eu tenho vergonha de dizer, mas eu vou fazer: eu vou visitar a sala de recurso, porque eu não conheço.

P2: Eu não conheço também. 
[Novamente boa parte do grupo concorda, afirmando que não conhece]

P5: Ah, eu conheço.

SR: É só ir lá.

P3: É sério, eu tenho vergonha. Eu vou, mesmo que não tenha ninguém. Alguém me abre. Porque eu nunca entrei numa sala de recursos.

SR: O que acontece: até o momento, a gente não tinha aluno na área [anos finais do ensino fundamental], então é diferente. Se perguntarem, no currículo [anos iniciais do ensino fundamental], no currículo eu to direto vendo com a professora, pego a prova, levo o aluno pra lá, faço com ele. Eu to sabendo quais são os conteúdos que estão trabalhando com eles. E é um estímulo também diferente, porque os menores e os com deficiência mais grave é um estímulo diferente: não trabalho diretamente com conteúdo, mas coisas que estimulem ele na aprendizagem. $\mathrm{Na}$ área, está sendo muito novo. Então, o que eu fiz? Eu atendo eles uma vez por semana. Tenho duas tardes só, na escola. [...] Então, ainda está muito... e eu ainda estou engatinhando nisso, também.

(Sessão 3)

A terceira ação de aprendizagem expansiva é a modelagem da nova solução que, na intervenção analisada, tomou forma na modelagem de um protocolo de organização da inclusão na escola, na agenda para os alunos incluídos e no estabelecimento de trabalho coordenado entre professores da sala regular e da sala de recursos. Essa ação consiste na elaboração de novos instrumentos, de um novo padrão para a atividade (Engeström, 2000; Engeström \& Sannino, 2010). A modelagem do protocolo ocorreu a partir de uma série de perguntas elaboradas pela pesquisadora que foi levando o grupo a repensar a própria organização e a tomar decisões na direção de melhorar a divisão do trabalho na escola, deixando claros os papéis de cada profissional, resgatando procedimentos que já tinham sido propostos em anos anteriores:
Pesquisadora: Como os professores fazem o encaminhamento para a avaliação, se percebem características diferentes? É formal?

CP: Não, os professores chegam pra mim e dizem: "Ó CP, acho que o fulano tem isso aqui". Então eu vou pegar e pedir pra SR dar uma olhada nele. Tudo mais ou menos assim.

P7: Tem um papel que a gente preenche.

P2: O ano passado, eu lembro que a gente tinha, esse ano não vi mais.

\section{$[\ldots]$}

P3: Eu vejo assim: depois que estruturar isso na escola, vai ficar fácil, entre aspas, porque aquele aluno que teve problema nos anos posteriores, já teve todo monitoramento dele. Ele vai estar monitorado. Aí, a única coisa que vai ter que variar é quando chegar um aluno novo.

(Sessão 4)

A modelagem da agenda iniciou em uma entrevista da qual participaram a mãe de uma aluna com deficiência e a professora da sala de recursos, ocasião em que a mãe solicitou que fossem desenvolvidas estratégias para ela que pudesse acompanhar o que acontecia na escola e ajudar a filha em casa. A mãe sugeriu que a escola lhe enviasse bilhetes com relatos e orientações. Essa sugestão foi sendo discutida e a professora da sala de recursos propôs a utilização de uma mesma agenda, por todos os professores, na qual iriam recados para a família, orientações quanto às lições de casa, provas e outras tarefas, ao invés de bilhetes soltos. O excerto que segue mostra a apresentação, feita pela pesquisadora, da transcrição da conversa da mãe com a professora da sala de recursos, na qual emergiu a ideia da agenda.

Pesquisadora: Na conversa que a gente teve com a mãe da E1, saiu uma ideia, uma possibilidade de trabalho com eles e com a família. A gente conversava sobre essa questão de a E1 não copiar as coisas a tempo e a mãe não sabia o que fazer de tema. Eu disse assim: [fala da pesquisadora na entrevista com a mãe e com a SR] "o que a gente podia 
fazer era mandar por escrito, mandar um bilhete, mandar alguma outra explicação. Se vocês ajudam em casa, quando vai no caderno e não sabe o que tem que fazer, precisa de uma explicação, buscar informações em tal lugar". [fala da mãe:] "Quem sabe essa mulher do meu sobrinho pergunte pros professores, mas perguntar um por um?!"; mais adiante [fala da mãe] "Eu não sei quando ela tem tarefa, porque ela nunca tem”. Daí eu digo [fala da pesquisadora:] "Os professores lá no início são acostumados a mandar bilhete e até o ano passado ela tinha isso". [fala da mãe:] "Era suficiente dar o bilhete pra E1, tem que fazer isso, isso e isso, aí eu sabia o que tinha que fazer. A E1 sempre vinha com as coisas. Hoje não to conseguindo acompanhar. $\mathrm{O} 6^{\circ}$ ano tá difícil de acompanhar, pra mim, e não tem esses bilhetes". A SR [fala:] "O que a gente podia fazer, de repente, era uma agenda, uma caderneta, uma agendinha pequena dela, que ali o professor possa anotar". Daí começou a nascer a ideia. [a mãe fala:] "Até compro uma agenda, uma caderneta pequeninha" [SR fala:] "Cada professor consegue fazer sua anotação e mandar a atividade, hoje tem tal coisa pra fazer". [mãe fala:] "Ela nunca tem atividade pra fazer". [pesquisadora fala:] "E se ela não copiar na aula, eles podem dar uma atividade impressa, eles passam a atividade e ela já tem ele impresso, faz uma cópia e manda bilhete" [SR fala:] "É, anota ali, tem atividade do livro, assim, assim”. [mãe fala:] "A E1 nunca tem tema pra fazer". [pesquisadora fala:] "O que podemos fazer é ter essa conversa com os professores pra tentar ajudar ela a se organizar"

(Sessão 8)

A modelagem da coordenação entre sala regular e sala de recursos não se consolidou em ferramentas concretas, como as duas anteriores. Ela foi acontecendo nas conversas entre os professores desses dois espaços, que passaram a se encontrar nas sessões da intervenção e planejar tarefas conjuntas pontuais como, por exemplo, o suporte da sala de recursos na realização das provas - tanto para refazê-las, na sala de recursos, como para elaborá-las de forma adaptada.

SR: Se tu der, como eu te falei da prova. Ele fez a prova com a turma. E aí tu recolhe a prova, tu me dá ela. E aí ele vem aqui. E aí eu converso com ele. Ele já fez a prova. Vamos refazer como exercícios.

P4: Vai ser sempre de quarta-feira, que eu tenho 2 períodos.

P5: Aí tu dá pra SR.

P4: Aí eu recolho. E, o que não estiver certo, ele vai fazer contigo.

SR: Pode ser.

(Sessão 5)

Da quarta etapa do ciclo de aprendizagem expansiva, o exame do novo modelo, que diz respeito a operar com o modelo criado para apreender sua dinâmica de funcionamento, identificando possíveis problemas e seu potencial (Engeström, 2000; Engeström \& Sannino, 2010), só há registro das transcrições da ação de coordenação entre professores da sala regular e da sala de recursos. Isso porque o protocolo deixou de ser retomado, após ser definido, e porque a agenda passou a ser utilizada sem ser reavaliada durante um período em que foram canceladas várias sessões da intervenção, justificadas pelo calendário escolar sem brechas para a realização das sessões interventivas. Assim, o novo modelo ficou sem acompanhamento. Nessa ação de exame da proposta de trabalho coordenado entre professores da sala regular e sala recursos, os sujeitos compreenderam que seria ineficaz, para a inclusão do aluno no cotidiano da sala de aula, apenas o suporte da sala de recursos em tarefas avaliativas esparsas.

P4: Sim, ele não aprende aquilo ali que a gente está trabalhando. Ele pode até aprender alguma coisa, mas como eu vou avaliar aquela outra coisa? Fica difícil. Eu fiz a prova dele menor, com perguntas bem simples, diferente da dos colegas, mas falando do conteúdo das aulas e ele não desenvolve. 
P7: Nem com a SR na sala de recursos?

P4: Com a SR sim, ela até fez, deixei um bilhete e tudo, lá ele fez.

P2: Mas se ele conseguiu fazer lá, alguma coisa da aula ele está pegando.

P4: Mas se tu pensar assim: só tem ela ali, lendo pra ele, fazendo perguntinha pra ele, ali ele tá desenvolvendo. Então eu vejo assim, na minha aula, ele não aprende nada, ele aprende lá com ela.

P2: Mas a SR reforça alguma coisa?

P4: Sim. Eu não vou dizer, assim, que um aluno especial, com aquele grau de comprometimento mental, está aprendendo na minha aula. Ultimamente, ele só desenha, não presta atenção. Eu mando ele copiar do quadro, ele não quer. Tanto que ele pegou o caderno e, quando eu vi, ele estava com aquele toquinho de coisa desenhando num pedacinho de papel desse tamanho. Quando eu chamei ele foi, mas logo voltou.

(Sessão 7)

Assim como em relação ao exame do novo modelo, há apenas os dados de implementação da coordenação do trabalho da professora de recursos com os professores da sala regular. A colaboração implementada consistiu em, além da realização das avaliações na sala de recursos, a professora dessa sala também organizar os pareceres gerais dos alunos a partir dos pareceres individuais de cada professor.

P3: Tu tem ele construído aí?

SR: O parecer?

P3: Do E2.

SR: Ah, mandei por e-mail. Fiquei pensando.

P3: Achei que tivesse ele impresso.

SR: Não. Eu mandei por e-mail pra CP.

P3: Cada um mandou um pedaço né? Tu juntou.

SR: Isso. Mas eu peço pra mandar pra vocês. É legal de ter de todos, isso. Aí eu coloquei por parágrafos. Vocês vão ver que aí, de alguns, eu tirei algumas coisas, porque já tá lá no início. AE1: escreve lento. Todos vocês colocaram isso. Que ela se relaciona bem com a turma, né? O E2 era quase que ao contrário do parecer da E1. Eu estava bem preocupada, assim, desde o início. Então, eu acho que se a gente pegar junto, tentar um caminho diferente com o E2, eu acho que a gente consegue, assim, que ele melhore, que ele tenha um desempenho melhor. Acho que, partindo dessa organização, né? como o P3 colocou: do caderno, o tema.

P3: Tu vai notar assim que pegar o caderno. Eu não sei se tu vai conseguir, vou ser sincero, não sei se tu vai conseguir ajudar a organizar o caderno.

(Sessão 5)

A implementação é quinta ação de aprendizagem expansiva, é a ação por meio da qual um novo modelo é aplicado (Engeström, 2000; Engeström \& Sannino, 2010). Da coordenação entre sala de recursos e sala regular manteve-se, até o fim do ano letivo, o refazer das provas em que os alunos tivessem obtido notas baixas, na sala de recursos, com a ajuda da professora, melhorando, assim, aparentemente, o desempenho acadêmico desses alunos. Também foi implementada a revisão dos pareceres descritivos de todos os professores, pela professora da sala de recursos, para que fossem apresentados, de maneira coerente, aos pais e à Secretaria de Educação.

A sexta etapa do ciclo de aprendizagem expansiva é a reflexão sobre o processo, ou seja, a avaliação do novo desenvolvido (Engeström \& Sannino, 2010). As reflexões predominaram na última sessão, já que foi organizada uma retrospectiva do que havia sido desenvolvido na intervenção. A conclusão foi que o protocolo não saiu do papel, pois, quando perguntados acerca da organização dos encaminhamentos relacionados aos alunos com deficiência, a confusão observada no início do ano ainda permanecia. Tal situação pode ser ilustrada com o caso de um aluno, cuja necessidade de acompanhamento especializado foi apontada por muitos professores, mas que, até o fim do ano, não tinha sido encaminhado para atendimento na sala de recursos. 
Pesquisadora: No encontro 3, a gente tentou começar a organizar a escola. Como se percebeu que não sabíamos ao certo quem eram os alunos, comecei a perguntar "quem informa vocês sobre esses alunos?", "quem faz o encaminhamento?", "quem avisa?" - daí era tudo a CP. Foi quando tentamos, com as fichas, fazer o caminho que o aluno percorria na escola. Desde então, isso ficou mais claro? Ajudou o trabalho de vocês? Mudou alguma coisa? Como ficou isso? Outros encaminhamentos foram feitos? No caso do E3, que se achava que tinha alguma coisa, como ficou? Como foi o encaminhamento dele?

P5: O E3.

P3: Parecer não tem.

Pesquisadora: Não, mas pergunto se quando não tem parecer e a gente percebe alguma característica. A SR apontou que se deveria fazer um encaminhamento escrito para uma avaliação.

CP: É que isso aí é assim, uma coisa extremamente demorada. Então isso aí, quando a gente faz, encaminha pra uma avaliação, às vezes ele só vai participar dessa avaliação no outro ano ainda.

Pesquisadora: Tá, mas ele foi encaminhado pra essa avaliação?

CP: Pois quem faz é a SR, então, eu não sei te dizer.

(Sessão 10)

A agenda, que foi apontada pelos sujeitos como ótima ideia, teve baixa adesão e os professores que aderiram a ela utilizaram-na por pouco tempo, pois não estavam acreditando que ela repercutiria em maior participação dos pais e na realização das tarefas pelos alunos.

P3: Mas a agenda é um meio de comunicação com os pais. O pai que tem que, diariamente, abrir a agenda e ver o que o filho fez.

SR: Mas nunca tinha nada na agenda.

CP: Não tinha nada.

P3: Tudo bem.
CP: Vieram os pais dos dois alunos. Tanto da E1, quanto do E2, vieram dizer que não tinha nada na agenda.

[P3 pergunta pros colegas quem escreveu. Falam juntos]

(Sessão 10)

O trabalho coordenado entre professores da sala regular e da sala de recursos foi a proposta que mais permaneceu, embora tenha ficado atrelada à avaliação dos alunos. Esse atrelamento resultou, segundo os professores, na diminuição do engajamento dos alunos, na sala de aula regular, já que iriam repetir os testes na sala de recursos.

P4: Ele vai estar na minha aula pra bonito! Porque eu to excluindo ele, porque eu não dou a mesma coisa. O E2, ultimamente, estava se achando - porque tudo pra ele era diferente. Ele já pegava a minha prova e dizia assim "Eu vou fazer depois com a SR?" "Vai." "Então tá". Pronto! Gente, o que tu quer mais que isso?! Se ele sabe que vai fazer depois. Eu to mentindo? Além de tudo, sou mentirosa?

SR: Não. A gente não precisa fazer a prova. A gente pode fazer outras coisas.

P4: Então, pro ano que vem, vocês já sabem: não pode dizer que ele vai fazer contigo. Que esse ano a gente fez isso, ele sabia que sempre ia fazer com a SR.

(Sessão 10)

A sétima ação de aprendizagem expansiva, a consolidação dos novos modelos, não chegou a ser levada a cabo em nenhuma das tentativas de expansão da compreensão e das práticas de inclusão. Ao final da intervenção, que coincidiu com o término do ano letivo, os professores seguiam apontando que a inclusão dos dois alunos com deficiência intelectual não estava sendo efetiva, no sentido de ser promotora da sua aprendizagem.

Resumindo, as três tentativas de aprendizagem expansiva, a partir da organização dos estímulos 
auxiliares na intervenção, não tiveram adesão dos sujeitos. Os sujeitos não se entendiam como responsáveis por qualquer mudança a ser realizada ou não a viam como possível.

É importante mencionar dois aspectos que podem ter contribuído para a não efetivação de mudanças. O primeiro diz respeito ao esmorecimento da preocupação em relação ao desenvolvimento de práticas pedagógicas inclusivas, como resultado de os professores descobrirem que os alunos incluídos tinham direito a serem avaliados por meio de critérios diferenciados daqueles utilizados em relação aos alunos sem deficiência. Isso, na prática, resultava que eles seriam aprovados diante de qualquer desempenho apresentado - é claro que a legislação não apresenta tal orientação, mas foi essa a interpretação feita das proposições legais de adaptação e flexibilização dos conteúdos, dos objetivos e da avaliação dos alunos com deficiência. O segundo aspecto está relacionado com o minimizar e relaxar a discussão da inclusão dos alunos com deficiência na escola, já os professores consideravam que havia muitos outros alunos com dificuldades mais sérias:

P4: Mas eu até to achando que tá melhor do que eu imaginava [referindo-se a inclusão de dois alunos com deficiência intelectual no $6^{\circ}$ ano do ensino fundamental].

P10: Também acho. A grande dificuldade não é com eles. Porque a gente entende as limitações que eles têm, consegue fazer uma avaliação. A dificuldade é com quem é dito normal e que não quer aprender. Aí a gente se preocupa de verdade. Porque atrás do especial tem toda uma preocupação, e aquele que não é especial? que a família tá nem aí, que tem um monte de dificuldade, mas que não tem nada?

(Sessão 4)

Nesse sentido, os docentes alegavam que a escola não era inclusiva para muitos outros alunos, além daqueles com deficiência, como pode ser observado nos trechos:
P4: A gente já não conseguia ajudar aqueles.

P3: Tu acha que os alunos normais também estão incluídos? Também não. Eles são excluídos pelo próprio processo, que vai se perpetuar na evasão escolar [...]

(Sessão 1)

P4: Ele tá ali, na mesma aula do E2. Ele não tem nenhum problema físico ou mental. Nada. Tu acha que eu - já é a terceira vez, eu acho, que dou aula pra ele - eu vejo progresso nele? Eu vejo cada vez o guri se afundar mais. Parece que menos ele faz, menos ele quer fazer [...] Eu olho pro E9, atirado naquela cadeira, sentado daquele jeito, tirou 2 e pouco. Faz 3 anos que ele vê essa matéria comigo, como é que vai tirar 2 e pouco numa prova? Pra ver como a escola teria que repensar muita coisa!

Pesquisadora: A escola não está ensinando!

P4: Está excluindo! E não tá acontecendo nada!

$[\ldots]$

P4: Não, eles não querem aprender.

(Sessão 9)

Estas manifestações merecem atenção, pois quando se reconhecem os vários processos de exclusão na escola, já não cabe discutir a escola inclusiva apenas a partir de propostas direcionadas aos alunos com deficiência. A inclusão desses alunos em uma escola que exclui muitos não promove uma educação inclusiva.

A inclusão via acesso formal à escola - a dita universalização do ensino - coloca os alunos em escolas sem condições adequadas de ensino para todos, nas quais os alunos não alcançam o mínimo dos conhecimentos esperados, conforme visto nas avaliações de larga escala - por exemplo, a Prova Brasil (Freitas, 2012). Tal reflexão sugere que contradições na inclusão dos alunos com deficiência não devem ser pensadas isoladamente, mas discutidas em relação a todos os alunos da escola. Nesse sentido, entende-se que a inclusão dos alunos com deficiência está ocorrendo em uma escola com uma série de aspectos a serem modificados. 
Embora sabendo das dificuldades para o planejamento e a implementação de práticas pedagógicas inclusivas, havia expectativa de mudança, na escola participante da intervenção, no sentido da elaboração de alternativas que promovessem a aprendizagem dos alunos com deficiência. Se não existisse tal expectativa - compartilhada pela escola, ao menos, inicialmente - não haveria razão de se propor uma pesquisa do tipo intervenção. Assim, ao planejar a intervenção, a hipótese que se tinha era de que a mudança no objeto (ou seja, na compreensão de inclusão) aconteceria se os motivos da atividade fossem transformados: o conceito de inclusão como apenas frequência à escola regular, passaria à inclusão definida como aprender na escola. Por meio de ações potencialmente expansivas, $o$ objeto foi abordado por diferentes caminhos: o da organização da escola, o da relação com a família e da atenção ao aluno, o da aproximação dos professores de sala regular e sala de recursos, para pensar coordenadamente a aprendizagem do aluno. Esses três caminhos, entretanto, não foram suficientes para alterar o objeto. Entende-se que, para haver transformação, seria necessário desenvolvimento de agency, ou seja, de engajamento dos professores no processo de mudança, o que não aconteceu.

Agency é definida como rompimento de um dado padrão de ações a partir da tomada de iniciativa para transformá-lo (Engeström, 2006, 2011; Virkkunen, 2006). A tomada de iniciativa estaria ligada aos artefatos externos dos quais o sujeito se apropria para redefinir o padrão da atividade, transformando a situação. As intervenções formativas são planejadas, então, para que o sujeito desenvolva agency a partir dos estímulos auxiliares que se vão organizando. Assim, além de essencial para as transformações expansivas do sistema de atividade, o desenvolvimento da agency é também resultado dessa aprendizagem expansiva (Engeström, Sannino, 2010).

Refletindo acerca do não desenvolvimento de agency, durante a intervenção, duas esferas merecem destaque. A primeira refere-se às condições que os professores tinham para lidar com a inclusão, principalmente no que se refere ao conhecimento e à formação para trabalhar com alunos com deficiência intelectual, bem como as condições de trabalho na escola e a perspectiva de que a escola era permeada por tantas dificuldades que a tornavam excludente para muitos. A segunda esfera refere-se à própria intervenção, que não forneceu subsídios - estímulos auxiliares - suficientes para edificar as ações de expansão, até a consolidação das novas práticas, ou seja, os elementos que organizaram as discussões não foram suficientes para empoderar os professores para a mudança. Neste sentido, há que se considerar a ausência da pesquisadora no dia a dia da escola, acompanhando os professores e o longo período entre cada sessão da intervenção.

\section{Considerações finais}

A teoria da aprendizagem expansiva é tomada como a coluna vertebral das intervenções formativas orientadas nos moldes do Laboratório de Mudança (Engeström, Rantavuori \& Kerosuo, 2013). Tendo, intencionalmente, o propósito de produzir modificações, de desencadear aprendizagens em um sistema de atividade (e pelo próprio sistema), torna-se central acompanhar as ações que produzem, ou que têm potencial para produzir tais modificações. $\mathrm{Na}$ intervenção relatada, a aprendizagem expansiva não se consolidou. Foram desencadeadas algumas ações com potencial expansivo, mas elas não se efetivaram, não modificaram a atividade.

A aprendizagem expansiva, conforme já dito, é acompanhada pelo processo de mudanças no objeto e não de mudanças no(s) sujeito(s). Embora os sujeitos possam também mudar, não é esse o foco, quando se analisa a aprendizagem expansiva. Examinando os indivíduos, pode-se pensar que algumas mudanças ocorreram: aumentou o conhecimento sobre inclusão, houve certa aproximação entre escola e famílias, entre professores da sala comum e a professora da sala de 
recursos. Contudo, a transformação da atividade (a aprendizagem expansiva), que requer um movimento do coletivo (do sistema), não ocorreu. As ações empreendidas pelos sujeitos, ao longo da intervenção, não podem ser consideradas transformações, mas parecem ter sido tentativas de ajustes (Engeström, 2017) para manter o atual modelo da escola frente às mudanças impostas pela inclusão dos alunos com deficiência. Há que se considerar ainda que as transformações necessárias à escola inclusiva vão além do trabalho realizado com os alunos com deficiência, são questões mais amplas relacionadas ao cotidiano, às condições objetivas e à cultura escolar, bem como às políticas públicas para a educação e para a educação inclusiva, que uma intervenção pontual não conseguiu abarcar.

\section{Referências}

Borowski, F. (2010). Fundamentos teóricos do curso de aperfeiçoamento de professores para o atendimento educacional especializado (2007): novos referenciais? (Disertación de maestría sin publicar), Universidad Federal de Santa Catarina, Florianópolis, SC, Brasil.

Brasil (2008). Política Nacional de Educação Especial na Perspectiva da Educação Inclusiva. Brasília: Ministério da Educação/Secretaria de Educação Continuada, Alfabetização, Diversidade e Inclusão (MEC/SECADI).

Damiani, M. F., Rochefort, R. S., Castro, R. F., Dariz, M. R., \& Pinheiro, S. S. (2013). Discutindo pesquisas do tipo intervenção pedagógica. Cadernos de Educação, 45, 57-67.

Engeström, Y. (2016). Aprendizagem expansiva. Campinas: Pontes Editores.

Engeström, Y. (1999). Activity theory and individual and social transformation. Em Y. Engeström, R. Miettinen, \& R. Punamäki (Orgs.) Perspectives on activity theory, (pp. 19-38). Cambridge University Press.
Engeström, Y. (2000). Activity theory as a framework for analyzing and redesigning work. Ergonomics, 47(7), 960-974.

Engeström, Y. (2001). Expansive learning at work: Toward an activity-theoretical reconceptualization. Journal of Education and Work, 14(1), 133-156.

Engeström, Y. (2006). Development, movement and agency: Breaking away into mycorrhizae activities. Em K. Yamazumi (Org.) Building activity theory in practice: Toward the next generation (pp.1-46). Osaka: Center for Human Activity Theory, Kansay University.

Engeström, Y. (2007). Putting Vygotsky to work: The change laboratory as an application of double stimulation. Em H. Daniels, M. Cole, \& J. V. Wertsch (Orgs.). The Cambridge Companion to Vygotsky (pp. 363-382). New York: Cambridge University Press.

Engeström, Y. (2011). From design experiments to formative interventions. Theory \& Psychology, 21(5), 598-628.

Engeström, Y. (2017). Improvement versus transformation. Éducation \& Didaticque, 11(2), 31-34.

Engeström, Y. \& Sannino, A. (2010). Studies of expansive learning: Foundations, findings and future challenges. Educational Research Review, $5(1), 1-24$.

Engeström, Y., Rantavuori, J., \& Kerosuo, H. (2013). Expansive Learning in a Library: Actions, cycles and deviations from instructional intentions. Vocations and learning, 6, 81-106.

Engeström, Y., Sannino, A., \& Virkkunen, J. (2014). On the methodological demands of formative interventions. Mind, Culture and Activity, 21(2), 118-128.

Fidalgo, S. S. (2018). A linguagem da exclusão e inclusão social na escola. São Paulo: Editora Unifesp.

Freitas, L. C. (2012). Os reformadores empresariais da educação: da desmoralização do magistério à destruição do sistema público de educação. Educação e Sociedade, 33 (119), 379-404. 
Garcia, R. M. C. (2013). Política de educação especial na perspectiva da educação inclusiva e a formação docente no Brasil. Revista Brasileira de Educação, 18 (52), 101-119.

Glat, R. (2018). Desconstruindo representações sociais: por uma cultura de colaboração para a inclusão escolar. Revista Brasileira de Educação Especial, 24, 9-20.

Leontiev, A. N. (1978). O desenvolvimento do psiquismo. Lisboa: Livros Horizonte.

Leontiev, A. N. (1983). Actividad, conciencia, personalidad. Havana: Editorial Pueblo y Educación.

Magalhães, R. C. B. P., \& Soares, M. T. N. Currículo escolar e deficiência: contribuições a partir da pesquisa-ação crítico-colaborativa. Cadernos de pesquisa, 46(162), 1124-1147.

Moraes, R. (2003). Uma tempestade de luz: a compreensão possibilitada pela análise textual discursiva. Ciência \& Educação, 9(2), 191-211.

Sannino, A. (2010). Sustaining a non-dominant activity in school: Only a utopia? Journal of Educational Change, 9, 329-338.

Sannino, A., \& Laitinen, A. (2015). Double stimulation in waiting experiment: Testing a Vygotskian model of the emergence of volitional action. Learning, Culture and Social Interaction, 4, 4-18.

Sannino, A., Engeström, Y., \& Lemos, M. (2016). Formative interventions for expansive learning and transformative agency. Journal of the Learning Sciences, 25(4), 599-633.
Souza, C. T. R., \& Mendes, E. G. (2017). Revisão sistemática das pesquisas colaborativas em educação especial na perspectiva da inclusão escolar no Brasil. Revista Brasileira de Educação Especial, 23(2), 279-292.

Tavares, L. M. F. R., Santos, L. M. M., \& Freitas, M. N. C. (2016). Educação inclusiva: um estudo sobre a formação docente. Revista Brasileira de Educação Especial, 22(4), 527-542.

Toledo, E. H., \& Vitaliano, C. R. (2012). Formação de professores por meio de pesquisa colaborativa com vistas à inclusão de alunos com deficiência intelectual. Revista Brasileira de Educação Especial, 18 (2), 319-336.

Virkkunen, J. (2006). Dilemmas in building shared transformative agency. Activités, 3(1), 43-66.

Virkkunen, J., \& Newnham, D. S. (2013). The change laboratory: A tool for collaborative developmental of work and education. Netherlands: Sense Publishers.

Vitaliano, C. R. (2019). Formação de professores de educação infantil para a inclusão de alunos com necessidades educacionais especiais: uma pesquisa colaborativa. Pro-posições, 30, 1-30.

Vygotsky, L. S. (1993). Obras escogidas (t. 2). Pensamiento y Lenguaje. Madrid: Visor.

Vygotsky, L. S., \& Luria, A. R. (1996). Estudos sobre a história do comportamento: símios, homem primitivo e criança. Porto Alegre: Artes Médicas. 